OPEN ACCESS

Edited by:

Allison B. Reiss,

New York University, United States

Reviewed by:

Nicholas Fitz,

University of Pittsburgh,

United States

Emmanuel Okoro,

Meharry Medical College,

United States

Shuyi Si,

Chinese Academy of Medical

Sciences, China

*Correspondence:

Gongbo Li

ligongbo@hospital.cqmu.edu.cn

Received: 08 February 2021

Accepted: 22 March 2021

Published: 11 May 2021

Citation:

Wu D, Hu Y, Song M and Li G (2021) Dichlorodipheny/trichloroethane Impairs Amyloid Beta Clearance By

Decreasing Liver $X$ Receptor $\alpha$

Expression.

Front. Aging Neurosci. 13:634948. doi: 10.3389/fnagi.2021.634948

\section{Dichlorodiphenyltrichloroethane Impairs Amyloid Beta Clearance by Decreasing Liver X Receptor $\alpha$ Expression}

\author{
Dongmei Wu, Yang Hu, Min Song and Gongbo Li* \\ Department of Neurology, The Second Affiliated Hospital of Chongqing Medical University, Chongqing, China
}

Abnormal amyloid beta $(A \beta)$ clearance is a distinctive pathological mechanism for Alzheimer's disease (AD). ATP-binding cassette transporter A1 (ABCA1), which mediates the lipidation of apolipoprotein $E$, plays a critical role in $A \beta$ clearance. As an environmental factor for AD, dichlorodiphenyltrichloroethane (DDT) can decrease ATP-binding cassette transporter $A 1$ (ABCA1) expression and disrupt $A \beta$ clearance. Liver $X$ receptor $\alpha$ $(L X R \alpha)$ is an autoregulatory transcription factor for ABCA1 and a target of some environmental pollutants, such as organophosphate pesticides. In this study, we aimed to investigate whether DDT could affect $A \beta$ clearance by targeting $L X R \alpha$. The DDT-pretreated $\mathrm{H} 4$ human neuroglioma cells and immortalized astrocytes were incubated with exogenous $A \beta$ to evaluate $A \beta$ consumption. Meanwhile, cytotoxicity and $L X R \alpha$ expression were determined in the DDT-treated cells. Subsequently, the antagonism of DDT on LXR $\alpha$ agonist T0901317 was determined in vitro. The interaction between DDT and LXR $\alpha$ was predicted by molecular docking and molecular dynamics simulation technology. We observed that DDT could inhibit A $\beta$ clearance and decrease the levels of $L X R \alpha$ mRNA and $L X R \alpha$ protein. Moreover, DDT is supposed to strongly bind to $L X R \alpha$ and exert antagonistic effects on $L X R \alpha$. In conclusion, this study firstly presented that DDT could inhibit $L X R \alpha$ expression, which would contribute to $A \beta$ clearance decline in vitro. It provides an experimental basis to search for potential therapeutic targets of AD.

Keywords: amyloid beta, dichlorodiphenyltrichloroethane, liver $\mathbf{X}$ receptor $\alpha$, Alzheimer's disease, ATP-binding cassette transporter A1

\section{INTRODUCTION}

Alzheimer's disease $(\mathrm{AD})$ is a neurodegenerative disease characterized by progressive loss of memory and other cognitive domains (Erkkinen et al., 2018). As the most common cause of dementia, AD affects about 30-46 million people worldwide (Caputo et al., 2020). With a global aging population, 75 million people are expected to suffer from AD in 2030 (Realdon et al., 2016). Owing to the lack of effective treatments for dementia, the current goal of $\mathrm{AD}$ is early detection and treatment to prevent the exacerbation of cognitive impairment. Except for early-onset familial $\mathrm{AD}$, the majority of late-onset $\mathrm{AD}$ is caused by the combination of genetic and environmental factors (Alzheimer's Association, 2013). As one of the most persistent and widely used organochlorine pesticides, 
dichlorodiphenyltrichloroethane (DDT) seems to be a critical environmental factor for AD (van Wendel De Joode et al., 2001; Singh et al., 2013; Richardson et al., 2014). Kim et al. (2015) have reported that the elders with high serum DDT concentration had about three times higher risks of low cognition. Based on a small study, DDT was found more often in $\mathrm{AD}$ brains $(n=7)$ than the control $(n=14)$ (Fleming et al., 1994). To screen out the potential targets of DDT-induced AD could be beneficial for the early detection and treatment of AD. Nevertheless, it remains unclear how DDT leads to $\mathrm{AD}$.

"Amyloid hypothesis" is the most widely accepted pathological mechanism for AD. According to this hypothesis, amyloid beta $(A \beta)$ pathology in the brain is followed by the development of neurofibrillary tau pathology and commences several years before obvious memory loss (Jack et al., 2009). As an initial step for $\mathrm{AD}$, the increased $\mathrm{A} \beta$ level is attributed to an imbalance between $A \beta$ production and $A \beta$ clearance (Bates et al., $2009)$. More notably, the vast majority of $A \beta$ accumulation is the result from deficient $A \beta$ clearance in microglia and astrocytes (Corona et al., 2016). ATP-binding cassette transporter A1 (ABCA1), which mediates the lipidation of apolipoprotein $\mathrm{E}$ (ApoE), is critical for $A \beta$ clearance (Koldamova et al., 2014). In $A \beta$ protein precursor transgenic mice, ABCA1 deletion aggravates $A \beta$ deposition and ABCA1 overexpression decreases $A \beta$ deposition (Wahrle et al., 2005, 2008). In our previous study (Li et al., 2015), DDT significantly decreased $A B C A 1$ protein expression. In addition, aberrant $A \beta$ clearance could be ameliorated when ABCA1 protein levels were rescued. Consequently, we proposed that ABCA1 could play an important role in deficient $A \beta$ clearance caused by DDT. However, few studies have investigated how DDT affects ABCA1 expression.

As an autoregulatory transcription factor, liver $\mathrm{X}$ receptor $\alpha$ $(\mathrm{LXR} \alpha)$ can activate ABCA1 expression by forming heterodimers with retinoic X receptor (Laffitte et al., 2001; Terwel et al., 2011; Wang et al., 2014). In transgenic mouse models of $\mathrm{AD}$, the LXR agonist can increase ABCA1 expression, decrease $A \beta$ deposition, and improve cognitive performance (Jiang et al., 2008). $\operatorname{LXR} \alpha$-null mice have lower brain ABCA1 levels at the age of 12 weeks old, when no amyloid plaques can be detected. It suggested that $\mathrm{LXR} \alpha$-regulated ABCA1 expression could be an early factor for $\mathrm{AD}$ progression (Zelcer et al., 2007). Recently, some environmental pollutants such as organophosphate pesticides can target the oxysterol-binding domain of $\operatorname{LXR} \alpha$ to inhibit $\operatorname{LXR} \alpha$ expression directly (Mozzicafreddo et al., 2015). Similar to organophosphate pesticides, DDT has obvious neurotoxicity and can regulate the expression of several nuclear receptors (Kelce et al., 1995; Medina-Diaz et al., 2007; Kazantseva et al., 2013). Therefore, we suspected that DDT could regulate LXR $\alpha$ expression directly. In this study, we aimed to explore the role of LXR $\alpha$ in DDT-induced $\mathrm{A} \beta$ deposition. $\mathrm{H} 4$ human neuroglioma cells and immortalized astrocytes were selected to evaluate $\mathrm{A} \beta$ clearance and $\mathrm{LXR} \alpha$ expression after DDT treatment. The interaction between DDT and $\operatorname{LXR} \alpha$ was predicted by molecular docking simulation technology. This study will provide evidence for elucidating the underlying mechanism of
DDT-induced $A \beta$ deposition, and for the potential therapeutic target of AD.

\section{MATERIALS AND METHODS}

\section{Reagents}

The following antibodies were used in this study: Actin (AC15) from Sigma-Aldrich (St Louis, MO, USA), A $\beta$ (82E1) from IBL International (Hamburg, Germany), and LXR $\alpha$ (ab41902) from Abcam Inc. (Cambridge, MA, USA). T0901317 (ab142808) was from Abcam Inc. (Cambridge, MA, USA). A $\beta_{40}$ monomers were purchased from American Peptide Company (Sunnyvale, CA, USA). 44-DDT (386340) from Sigma-Aldrich (St. Louis, MO, USA) was dissolved into $10 \mathrm{mM}$ stock solution in dimethyl sulfoxide (DMSO). Alamarblue ${ }^{\circledR}$ cell viability reagent, Dulbecco's modified Eagle's medium (DMEM), and Trizol reagent were purchased from Invitrogen Company (Carlsbad, CA, USA). High capacity cDNA transcription kit was supplied by Applied Biosystems (Foster City, CA, USA). Tris-Tricine gel, Tris-Glycine extended (TGX ${ }^{\mathrm{TM}}$ ) gel, and 0.2$\mu \mathrm{m}$ pore size nitrocellulose membrane were supplied by Bio-Rad Laboratories Incorporation (Hercules, CA, USA). RIPA buffer was purchased from Millipore Corporation (Bedford, MA, USA). Fresh serum-free DMEM supplemented N2 was obtained from BRL (Grand Island, NY, USA). EDTA-free protease inhibitor cocktail was provided by Roche (Mannheim, Germany). BCA protein assay kit was obtained from Thermo Fisher Scientific (Waltham, MA, USA). Lumigen TMA-100 ECL detection kit was from Lumigen Inc. (Southfield, MI, USA). Real-time reversetranscription PCR (RT-PCR) kit (including Premix Ex Taq and SYBR Green I) was purchased from Takara Biotechnology Company Limited, Ltd. (Dalian, China). The other chemical reagents were of analytical grade.

\section{Cell Culture}

H4 human neuroglioma cells were cultured in DMEM with $10 \%$ fetal bovine serum and $1 \%$ penicillin/streptomycin. Immortalized astrocytes, which were derived from ApoE3targeted replacement mice (Zhao et al., 2014), were maintained in DMEM/F-12 with $20 \%$ fetal bovine serum, 2 mM L-glutamine, glutamine, $1 \mathrm{mM}$ sodium pyruvate, $1 \times$ nonessential amino acids, and $1 \%$ penicillin/streptomycin. All the cells were incubated at $37^{\circ} \mathrm{C}$ in a humidified $5 \% \mathrm{CO}_{2}$ incubator. For cytotoxicity assay, cells were seeded and cultured overnight in 96-well plates. For protein and mRNA detection, cells were seeded on the day before treatments in 12-well plates. When the cells were at a confluence of $70 \%$, the incubated cells were treated with $0.1 \%$ DMSO vehicle (as the negative control), $1 \mu \mathrm{M}$ DDT, and $10 \mu \mathrm{M}$ DDT, respectively. Based on our previous study (Li et al., 2015), $1 \mu \mathrm{M}$ DDT slightly increased A $\beta$ levels and $10 \mu \mathrm{M}$ DDT had the most dramatic effect on $\mathrm{A} \beta$ levels.

\section{Cytotoxicity Assay}

The incubated cells were pretreated with DDT or DMSO vehicle for $48 \mathrm{~h}$. Based on the manufacturer's guide, the in vitro cytotoxic effects of DDT were measured by the Alamarblue ${ }^{\circledR}$ cell viability reagent. 


\section{A $\beta$ Clearance Assay}

The incubated cells were pretreated with DDT or DMSO vehicle for $24 \mathrm{~h}$. After the removal of media, cells were treated with the fresh serum-free DMEM supplemented N2 containing DDT or DMSO and incubated with $200 \mathrm{nM} \mathrm{A} \beta_{40}$ monomers dissolved in DMSO for $24 \mathrm{~h}$. Subsequently, the media were collected and separated on a $16.5 \%$ Tris-Tricine gel. The cellular lysates were separated on a $4-20 \% \mathrm{TGX}^{\mathrm{TM}}$ gel. The levels of $\mathrm{A} \beta$ were determined via Western blotting analysis. All the experiments were repeated independently three times. The cells were divided into three groups and were respectively treated with T0901317, T0901317 with DDT, and DMSO vehicle for $24 \mathrm{~h}$. After the removal of media, cells were treated with the fresh serum-free DMEM supplemented N2 containing T0901317, T0901317 with DDT, or DMSO vehicle and then incubated with $200 \mathrm{nM} \mathrm{A} \beta_{40}$ monomers dissolved in DMSO for another $24 \mathrm{~h}$. The cellular lysates were separated on a $4-20 \% \mathrm{TGX}^{\mathrm{TM}}$ gel. The levels of $\mathrm{A} \beta$ in the remaining medium were determined via Western blotting analysis.

\section{RNA Isolation and Real-Time RT-PCR}

The incubated cells were pretreated with DDT or DMSO vehicle for $48 \mathrm{~h}$. Total RNAs were extracted using the Trizol reagent and reverse transcribed with the high-capacity cDNA transcription kit following the manufacturer's instruction. Real-time RT-PCR was performed in triplicate in 20- $\mu \mathrm{l}$ volumes in 96-well plates with StepOnePlus system from Applied Biosystems. Glyceraldehyde phosphate dehydrogenase (GAPDH) was selected as a normalization control. Relative mRNA levels were calculated by comparative Ct method. The primers were designed by Methyl Primer Express 1.0 from Applied Biosystems. The primers of human GAPDH were as follows: forward 5'-CAAGGGCATCCTGGGCTAC-3'; reverse $5^{\prime}$-TTGAAGTCAGAGGAGACCACCTG-3'. The primers of mouse GAPDH were as follows: forward $5^{\prime}$-AGGTCGGTGT GAACGGATTTG-3'; reverse 5'-TGTAGACCATGTAGTTGA GGTCA-3'. The primers of human $\mathrm{LXR} \alpha$ were as follows:

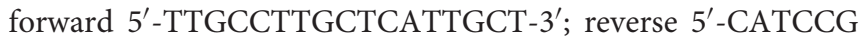
TGGGAACATCA- $3^{\prime}$. The primers of mouse LXR $\alpha$ were as follows: forward $5^{\prime}$-GCTCATTGCCATCAGCAT-3'; reverse 5'-AGCATCCGTGGGAACATCA-3'.

\section{Western Blotting Analysis}

The incubated cells were pretreated with T0901317, T0901317 with DDT, or DMSO vehicle for $48 \mathrm{~h}$. Subsequently, the incubated cells were lysed in RIPA buffer with EDTA-free protease inhibitor cocktail at $4^{\circ} \mathrm{C}$ for $30 \mathrm{~min}$. Subsequently, the incubated cells were centrifuged at $17,000 \times g$ for $10 \mathrm{~min}$ and the supernatants were collected. Protein concentration was quantified using the BCA protein assay kit. Equal amounts of total protein for each lysate were separated on a $4-20 \%$ $\mathrm{TGX}^{\mathrm{TM}}$ gel and transferred to $0.2-\mu \mathrm{m}$ pore size nitrocellulose membranes. Membranes were treated with specific primary antibodies and peroxidase-conjugated secondary antibodies, and developed using the Lumigen TMA-100ECL detection kit. LAS4000 was employed for image collection. All the experiments were repeated independently at least three times.

\section{Molecular Docking and Molecular Dynamics Simulation}

Molecular docking study was performed to investigate the binding mode between the DDT and the LXR $\alpha$ using AutoDock Vina 1.1.2 (Trott and Olson, 2010). The three-dimensional (3D) structure of the LXR $\alpha$ (PDB ID: 3IPQ) was downloaded from the RCSB database ${ }^{1}$. The $3 \mathrm{D}$ structure of the DDT was drawn by ChemBioDraw Ultra 14.0 and ChemBio3D Ultra 14.0 software. The AutoDockTools 1.5.6 package (Sanner, 1999; Morris et al., 2009) was employed to generate the docking input files. The binding site of the LXR $\alpha$ was identified as center_x: 43.079 , center_y: 16.295 , and center_z: -6.463 with dimensions size_x: 15, size_y: 15 , and size_z: 15 . In order to increase the docking accuracy, the value of exhaustiveness was set to 20. For Vina docking, the default parameters were used if it was not mentioned. Then, the molecular dynamics study was performed to revise the docking result.

The Amber 14 (Götz et al., 2012; Pierce et al., 2012; SalomonFerrer et al., 2013) and AmberTools 15 programs were used for molecular dynamics simulation of the selected docked pose. Cryptotanshinone was first prepared by ACPYPE (Sousa Da Silva and Vranken, 2012), a tool based on ANTECHAMBER (Wang et al., 2004, 2006) for generating automatic topologies and parameters in different formats for different molecular mechanics programs, including calculation of partial charges. Then, the force field "leaprc.gaff" (generalized amber forcefield) was used to prepare the ligand, while "leaprc.ff14SB" was used for the receptor. The system was placed in a rectangular box (with a 10.0- $\AA$ boundary) of TIP3P water using the "SolvateOct" command with the minimum distance between any solute atoms. Equilibration of the solvated complex was done by carrying out a short minimization (2,000 steps of each steepest descent and conjugate gradient method), 1,000 ps of heating, and 500 ps of density equilibration with weak restraints using the GPU accelerated PMEMD (Particle Mesh Ewald Molecular Dynamics) module. At last, 40 ns of molecular dynamics simulations was carried out. All the molecular dynamics analysis was performed on Dell Precision T5500 workstation.

\section{Binding Free Energy and Energy Decomposition Per Residue Calculation}

The binding free energies $\left(\Delta G_{\text {bind }}\right.$ in $\left.\mathrm{kcal} / \mathrm{mol}\right)$ were calculated using the Molecular Mechanics/Generalized Born Surface Area (MM/GBSA) method, implemented in AmberTools 15. Moreover, to identify the key protein residues responsible for the ligand binding process, the binding free energy was decomposed on a per-residue basis. For each complex, the binding free energy of MM/GBSA was estimated as follows: $\Delta G_{\text {bind }}=G_{\text {complex }}-G_{\text {protein }}-G_{\text {ligand }} . \Delta G_{\text {bind }}$ was the binding free energy and $G_{\text {complex }}, G_{\text {protein }}$, and $G_{\text {ligand }}$ were the free energies of complex, protein, and ligand, respectively.

\section{Statistical Analysis}

SPSS 15.0 from SPSS Science Incorporation (Chicago, IL, USA) and GraphPad Prism 5.0 from GraphPad Software (La Jolla, CA,

\footnotetext{
${ }^{1}$ www.rcsb.org
} 


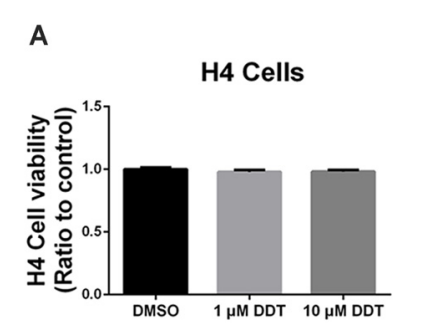

B

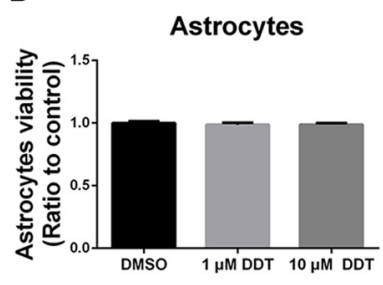

FIGURE 1 | Dichlorodiphenyltrichloroethane (DDT)-related cytotoxicity in H4 human neuroglioma cells and immortalized astrocytes. (A) Viability of $\mathrm{H} 4$ human neuroglioma cells. (B) Viability of immortalized astrocytes. Mean \pm SEM, $n=3$.

USA) were employed for data analysis. All the data were shown as mean \pm SEM. First, the equal variance test (Levene Median test) and normality test (Kolmogorov-Smirnov test) were used to determine the statistical significance. The two-tailed Student's $t$-test was used when the data meet the assumptions of parametric testing. Statistical significance was set at $P<0.05$.

\section{RESULTS}

\section{Cytotoxicity Under DDT Exposure}

The acute high dose of DDT exposure may result in nonspecific cytotoxicity, which is responsible for the poor cell viability and performance. Thus, Alamarblue ${ }^{\circledR}$ assay was used to investigate whether the DDT doses in this study could trigger nonspecific cytotoxicity in H4 human neuroglioma cells (Figure 1A) and immortalized astrocytes (Figure 1B). Compared to the negative control DMSO group, no obvious cell toxicity was shown in cells treated with either $1 \mu \mathrm{M}$ DDT or $10 \mu \mathrm{M}$ DDT.

\section{A $\beta$ Clearance Under DDT Exposure}

Because H4 human neuroglioma cells and immortalized astrocytes cannot secrete detectable $\mathrm{A} \beta$ endogenously, we employed these cells to assess the ability of A $\beta$ clearance. At first, the incubated cells were pretreated with DDT or DMSO vehicle for $24 \mathrm{~h}$. After the removal of media with serum, cells were treated with the fresh serum-free media containing DDT or DMSO and incubated with $200 \mathrm{nM} \mathrm{A} \beta_{40}$ for another $24 \mathrm{~h}$. The levels of the remaining $A \beta$ in the media were then examined by Western blotting analysis. As shown in Figures $\mathbf{2 A}, \mathbf{B}$, the DDT treatment group exhibited much more $A \beta$ remaining in the media than the control group, especially the $10 \mu \mathrm{M}$ DDT group. According to the increasing tendency from the semiquantitative assay (Figures $2 \mathrm{C}, \mathrm{D}, P<0.01$ ), the higher dose of DDT exposure could cause more $A \beta$ remaining in the media. These results suggested that DDT could impair $\mathrm{A} \beta$ clearance in vitro. Exposure to $10 \mu \mathrm{M}$ DDT could result in more obvious $\mathrm{A} \beta$ deposition without nonspecific cytotoxicity, which provides a suitable DDT dose for our further in vitro experiments about evaluating the effects of DDT on LXR $\alpha$.

\section{LXR $\alpha$ Expression Under DDT Exposure}

Our previous study demonstrated that ABCA1 expression is downregulated by DDT treatment. Because ABCA1 is a critical target of LXR $\alpha$ in brain, we proposed that $\mathrm{LXR} \alpha$ may account for the DDT-ABCA1 molecular pathway. According to the results in Figure 3, H4 human neuroglioma cells and immortalized astrocytes were treated with $10 \mu \mathrm{M}$ DDT to evaluate the effects of DDT on LXR $\alpha$ expression. Compared to the DMSO control group, the DDT group exhibited significantly lower concentration of LXR $\alpha$ mRNA (Figures 3A,B, $P<0.001$ ). Likewise, the DDT group demonstrated a lower content of LXR $\alpha$
A

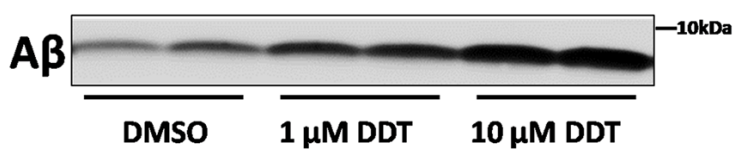

C

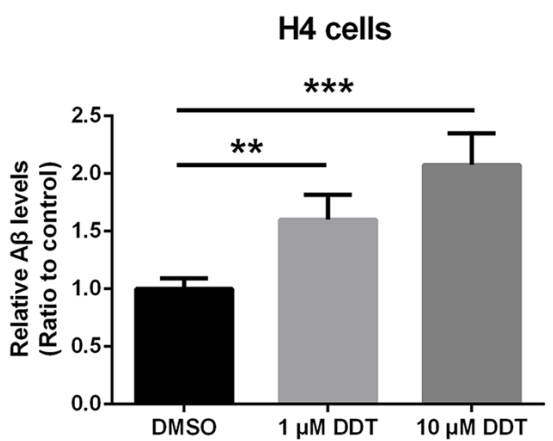

B

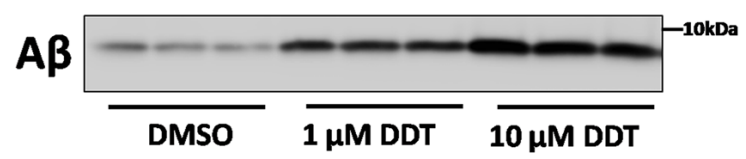

D

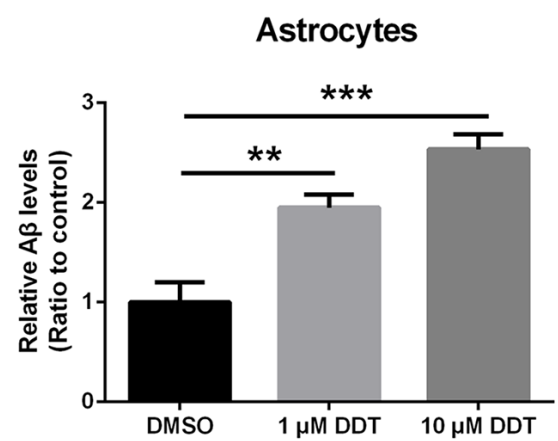

FIGURE 2 | DDT decreases amyloid beta (A $\beta$ ) clearance in $\mathrm{H} 4$ human neuroglioma cells and immortalized astrocytes. (A) The remaining $A \beta$ in $\mathrm{H} 4$ human neuroglioma cells media; (B) the remaining $A \beta$ in immortalized astrocytes media; (C) semiquantitative analysis of $A \beta$ in $\mathrm{H} 4$ human neuroglioma cells media; (D) semiquantitative analysis of $\mathrm{A} \beta$ in immortalized astrocytes media. Mean $\pm \mathrm{SEM}, n=6,{ }^{\star \star} P<0.01 \mathrm{vs}$. control, ${ }^{\star \star \star} P<0.001$ vs. dimethyl sulfoxide (DMSO) control group. 


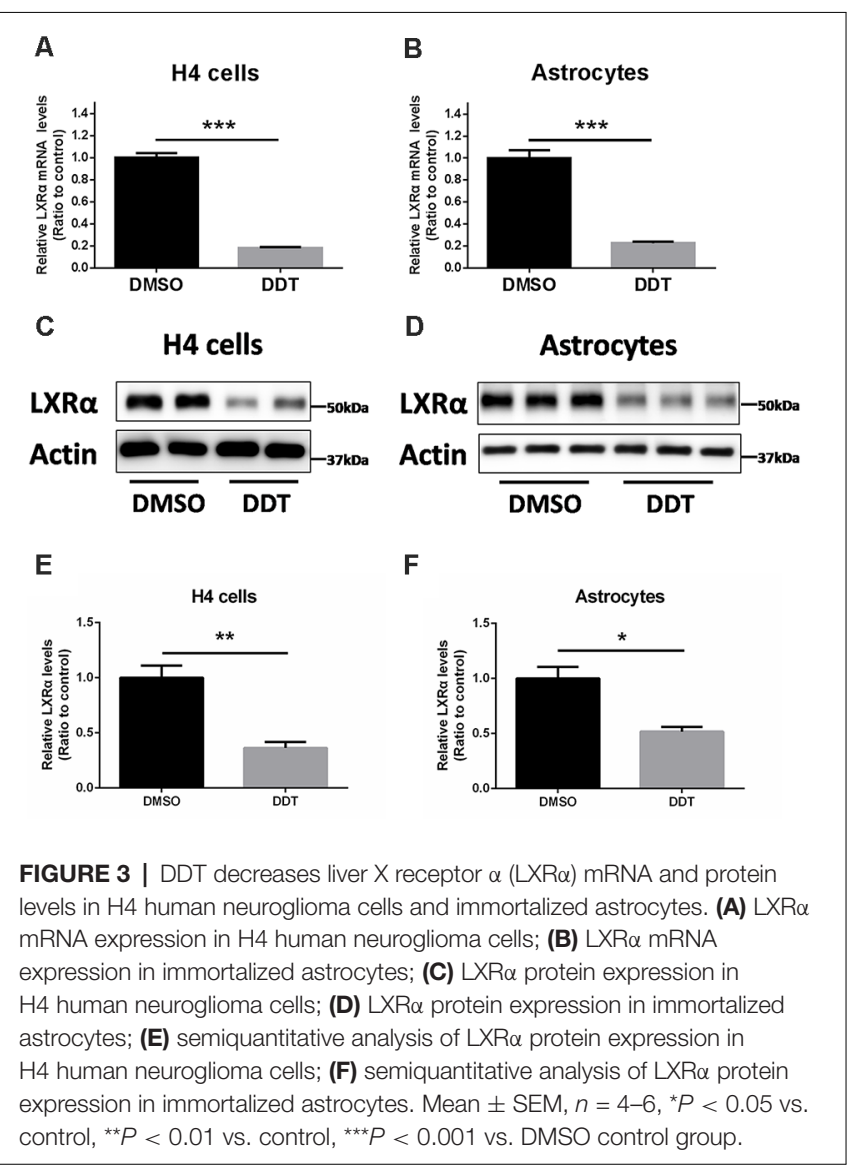

protein than the control (Figures 3C,D). The semiquantitative assay of $\operatorname{LXR} \alpha$ protein also showed a statistically significant difference between these two groups (Figures 3E,F, $P<0.05$ ). It suggested that DDT could decrease LXR $\alpha$ expression in vitro.

\section{Autoregulation of $L X R \alpha$ and Antagonistic Effects of DDT on LXR $\alpha$}

Autoregulation of the $\operatorname{LXR} \alpha$ gene is an important component of lipid-inducible efflux pathway in human macrophages (Laffitte et al., 2001). It is unknown whether this autoregulation exists in $\mathrm{H} 4$ human neuroglioma cells. According to the results in Figure 4A, H4 human neuroglioma cells were treated with $10 \mu \mathrm{M} \mathrm{LXR} \alpha$ agonist T0901317. Compared to the DMSO control group, the T0901317 group significantly increased ABCA1 and LXR $\alpha$ protein levels, as well as enhanced $A \beta$ clearance. The T0901317+DDT group exhibited lower ABCA1 protein levels, lower $\mathrm{LXR} \alpha$ protein levels and poorer $\mathrm{A} \beta$ clearance than the T0901317 group. These results implied that DDT exerted an antagonistic effect on this autoregulation. The semiquantitative assay of $\mathrm{ABCA} 1, \mathrm{LXR} \alpha$, and $\mathrm{A} \beta$ protein also showed a statistically significant difference between these groups (Figure 4B, $P<0.01$ ). These data suggested that LXR $\alpha$ agonist T0901317 could activate LXR $\alpha$ expression and LXR $\alpha$ may bind to its own promoter to enhance its transformation. DDT may compete for the binding site of LXR $\alpha$ with LXR $\alpha$ agonist to exert antagonistic effects.

\section{Molecular Dynamics Results}

To determine the competition of DDT with LXR $\alpha$ agonist T0901317 and explore the potential binding mode between the DDT and the $\operatorname{LXR} \alpha$, molecular docking and molecular dynamics simulation were performed using the AutoDock Vina 1.1.2 and Amber14 software package. The binding mechanism of LXR $\alpha$ with DDT was determined by $40-n s$ molecular dynamics simulation based on the docking results. To explore the dynamic stability of the complex and to ensure the rationality of the sampling strategy, the root-mean-square deviation (RMSD) values of the protein backbone based on the starting structure along the simulation time were calculated and plotted in Figure 5A. As shown in Figure 5A, the protein structures of the two systems were stabilized during the 40 -ns simulation.

The root-mean-square fluctuations (RMSF) of the residues of the whole protein in the LXR $\alpha$-DDT complex and in the free LXR $\alpha$ were calculated to reveal the flexibility of the residues. The RMSF of these residues are shown in Figure 5B, clearly depicting different flexibilities in the binding site of LXR $\alpha$ between the presence and absence of the DDT. The majority of the residues in the LXR $\alpha$ binding site that bind with DDT showed a small degree of flexibility with a RMSF of less than $2 \AA$ when compared with the free $\operatorname{LXR} \alpha$, indicating that these residues seem to be more rigid as a result of binding to DDT.

To gain more information about the residues surrounding the binding site and their contribution to the system, the electrostatic, Van der Waals, solvation, and total contribution of the residues to the binding free energy were calculated with the MMGBSA method. The summations of the per-residue interaction free energies were separated into Van der Waals $\left(\Delta E_{v d w}\right)$, solvation $\left(\Delta E_{\text {sol }}\right)$, electrostatic $\left(\Delta E_{\text {ele }}\right)$, and total contribution $\left(\Delta E_{\text {total }}\right)$. In the LXR $\alpha$-DDT complex, the residues Phe-315 and Phe-326 with the $\Delta E_{v d w}$ of $<-1.8 \mathrm{kcal} / \mathrm{mol}$ (Figure 5C) showed an appreciable Van der Waals interactions with the DDT because of the close proximity between the residues and the DDT, forming $\mathrm{CH}-\pi$ interaction and $\mathrm{Cl}-\pi$ interaction, respectively (Figure 5D). Except for the residues Phe-315 and Phe-326, the majority of the decomposed energy interaction originated from Van der Waals interactions, apparently through hydrophobic interactions (i.e., Phe-257, Leu260, Ala-261, Met-298, Leu-299, Leu-331, Ile-336, Ile-339, Leu428, and Trp-443). In addition, the total binding free energy for the LXR $\alpha$-DDT complex calculated according to the MMGBSA approach, and the estimated $\Delta G_{\text {bind }}$ of $-36.5 \mathrm{kcal} / \mathrm{mol}$ was found for DDT, suggesting that DDT could strongly bind to LXR $\alpha$ and interact with the binding site of LXR $\alpha$. In summary, the above molecular simulation gave a rational explanation of the interactions between DDT and $\mathrm{LXR} \alpha$, which provided valuable information for the $\operatorname{LXR} \alpha$ antagonist.

\section{DISCUSSION}

In the past few decades, $\mathrm{AD}$ pathogenesis has been focused on the genetic mechanisms. Recently, environmental factors contributing to $\mathrm{AD}$ are drawing more and more attention (Hayden et al., 2010; Iraola-Guzman et al., 2011; Singh et al., 
A

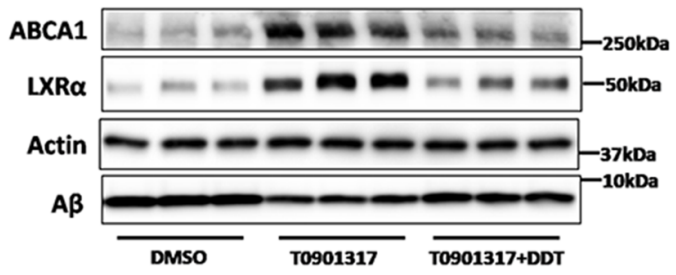

B

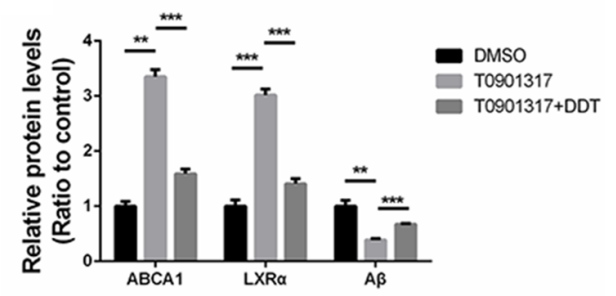

FIGURE 4 | LXR $\alpha$ agonist T0901317 upregulates LXR $\alpha$ protein levels and DDT antagonizes this autoregulation. (A) ATP-binding cassette transporter A1 (ABCA1) and $\mathrm{LXR} \alpha$ protein expression in $\mathrm{H} 4$ human neuroglioma cells, as well as the remaining amyloid beta (A $\beta$ ) in $\mathrm{H} 4$ human neuroglioma cells media. (B) Semiquantitative analysis of protein levels. Mean $\pm \mathrm{SEM}, n=3,{ }^{\star \star} P<0.01$ vs. DMSO control group, ${ }^{\star \star *} P<0.001$ vs. T0901317 group.

A

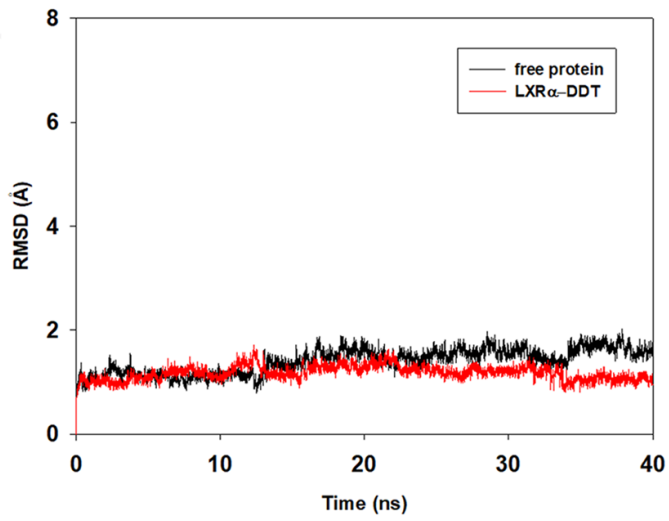

C

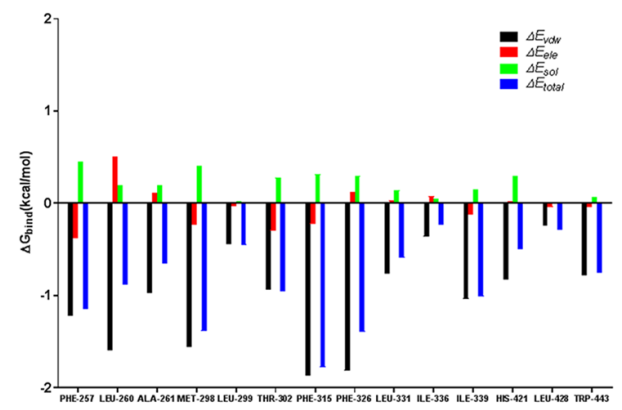

B

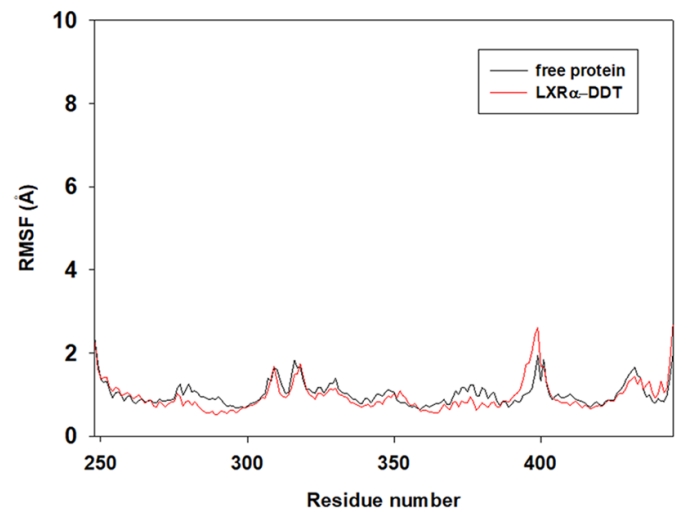

D

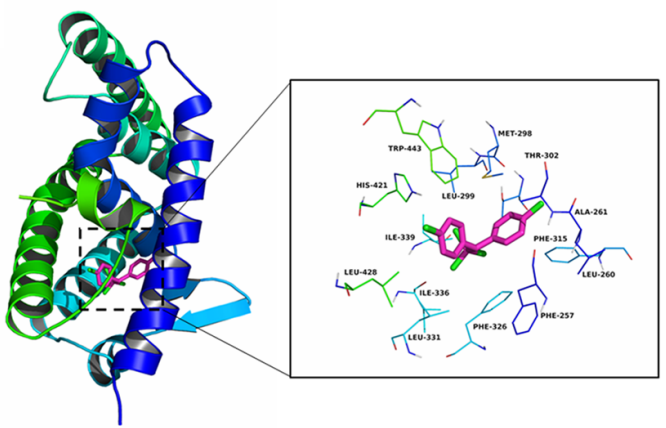

FIGURE 5 | Molecular docking and molecular dynamics simulation indicates $L X R \alpha$ could bind to LXR $\alpha$ protein. (A) The root-mean-square deviations (RMSD) of all the atoms of the LXR $\alpha$-DDT complex with respect to its initial structure as a function of time. (B) The root-mean-square fluctuations (RMSF) of residues of the whole protein in the LXR $\alpha$-DDT complex and free LXR $\alpha$ during the 40-ns simulation. (C) Decomposition of the binding energy on a per-residue basis in the LXR $\alpha$-DDT complex. (D) The predicted binding mode of DDT in LXR $\alpha$ binding pocket obtained from molecular dynamics simulation.

2013; Billioti De Gage et al., 2014; Richardson et al., 2014). As an organochlorine pesticide strongly associated with AD, DDT has been extensively used as a broad-spectrum insecticide in agriculture since World War II (Davies et al., 2007; Greenwood, 2014). The common use of DDT in agriculture was banned in the 1970s-1980s, but DDT is still used for controlling disease vectors responsible for malaria and the Zika virus in developing countries (Wnuk et al., 2020). DDT is known to bioaccumulate in human and is negatively associated with cognitive scores (Kiyosawa et al., 2008; Kim et al., 2015). DDT will be metabolized into a major and more stable derivative, dichlorodiphenyldichloroethylene (DDE), which can accumulate in organs for a long time that are rich in adipose tissue, such as the brain (Di et al., 2017). Recently, the concept of an AD exposome was reviewed by Finch and Kulminski (2019). They addressed major gaps in understanding environmental contributions to the $\mathrm{AD}$. $\mathrm{AD}$ is characterized by the impaired clearance of brain $\mathrm{A} \beta$ (Wildsmith et al., 2013). Our previous study has shown that DDT could dramatically decrease A $\beta$ clearance in $\mathrm{H} 4$ human neuroglioma cells, which provides a potential mechanism for 


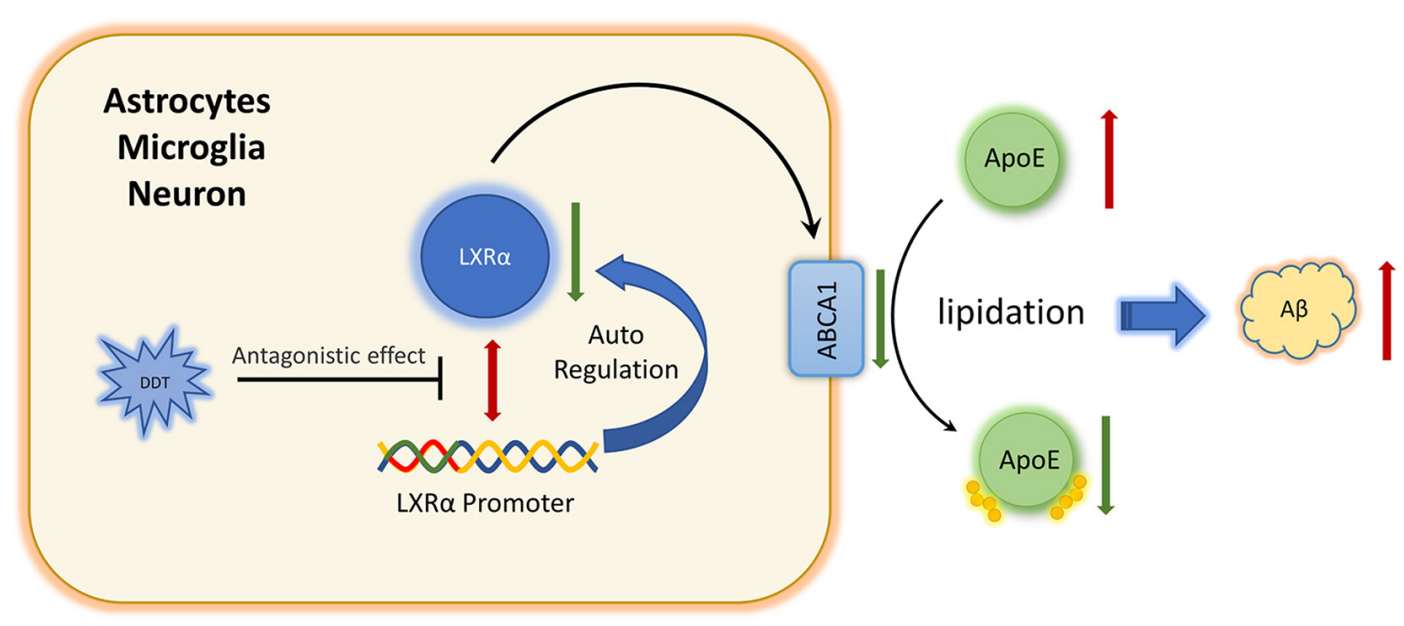

FIGURE 6 | Schematic diagram of DDT impairs amyloid beta (A $\beta$ ) clearance via antagonizing LXR $\alpha$.

DDT-induced AD (Li et al., 2015). Astrocytes play an essential role in $A \beta$ clearance and are widely used for $A \beta$ study (Zhao et al., 2014). These two types of cells cannot secrete detectable $A \beta$ endogenously, in which the clearance of exogenous $A \beta$ can be measured accurately without the confounding effects of endogenous $A \beta$. Thus, the abovementioned cells were selected to investigate how DDT impairs $A \beta$ clearance in this study. It is not practical for a long-term chronic DDT exposure in cell culture. As to acute high-dose exposure, it is essential to select a suitable dose in cell experiments. In line with our previous study, $10 \mu \mathrm{M}$ DDT can inhibit $\mathrm{A} \beta$ clearance much heavier than $1 \mu \mathrm{M}$ DDT without obvious cell toxicity. Approximately $10.2 \mu \mathrm{M}$ DDE has been found in human serum samples from elderly individuals (Kim et al., 2015); most of the subjects were exposed to DDT for the whole lifetime, the exposure levels to DDT in older persons were presumably much higher when they were younger, and they have likely experienced a higher body burden during their lifetime than what we can estimate from the current serum concentrations (Kim et al., 2015). In addition, we used $10 \mu \mathrm{M}$ DDE to perform the same assay and had the much similar results (data not shown). In our opinion, $10 \mu \mathrm{M}$ DDT exposure should be reasonable in the current study.

Due to the similar rate of $A \beta$ production and clearance, even minor deficits in $A \beta$ clearance will lead to $A \beta$ accumulation (Corona et al., 2016). Cumulatively, ABCA1-mediated ApoE lipidation is thought to be necessary for the efficient clearance of $\mathrm{A} \beta$ and the improvement of cognitive impairment (Wahrle et al., 2008; Corona et al., 2016; Fitz et al., 2017). Interestingly, dysfunctional $\mathrm{ABCA} 1$ contributes to the development of type 2 diabetes through increased cholesterol levels in pancreatic $\beta$-cells (Koldamova et al., 2014). In addition, ABCA1 can interact with other genetic risk factors (such as ApoE4) to worsen the AD phenotype (Fitz et al., 2017). Previously, we have identified for the first time that ABCA1 is the downstream target gene adversely affected by DDT (Li et al., 2015). However, it remains unclear how $\mathrm{DDT}$ regulates $\mathrm{ABCA1}$ expression. In $\mathrm{AD}$ mouse models, the agonists of nuclear receptors have been proven to reduce $A \beta$ pathology and improve cognition (Skerrett et al., 2014). To our knowledge, ABCA1 is transcriptionally regulated by $\operatorname{LXR} \alpha$, which is a nuclear receptor. LXR activation has been regarded as a top biological pathway to ameliorate AD-related cognitive impairment and $A \beta$ accumulation (Niculescu et al., 2020). Among the LXR subtypes, LXR $\alpha$ mainly mediates the metabolism of cholesterol and $\mathrm{A} \beta$ in the brain (Terwel et al., 2011). In our present study, we observed significantly lower concentration of LXR $\alpha$ mRNA and protein in $\mathrm{H} 4$ human neuroglioma cells and immortalized astrocytes treated with $10 \mu \mathrm{M}$ DDT. Combined with our previous results, we speculated that DDT could inhibit $\mathrm{LXR} \alpha$ expression to disrupt $\mathrm{ABCA} 1$ expression and $\mathrm{A} \beta$ clearance.

Furthermore, we are wondering how DDT affects LXR $\alpha$ expression. To our knowledge, LXR $\alpha$ is a ligand-activated transcription factor with the ability of positive autoregulation (Laffitte et al., 2001). Some environmental pollutants, such as organophosphates, have been reported to act like ligands or modulators to affect LXR $\alpha$ activity via binding to the oxysterolbinding domain of LXR $\alpha$ directly (Mozzicafreddo et al., 2015). DDT and organophosphates have structural similarities in their chemical features. Our present study also implied that DDT could have the antagonistic effects on LXR $\alpha$. It has been reported that DDT could regulate the activity of estrogen receptors by binding to estrogen receptors directly (Frigo et al., 2005; Matsushima, 2018). Additionally, our present molecular docking simulation analysis suggested that DDT could bind to LXR $\alpha$ directly and become a stable bimolecular complex. Moreover, the binding site (i.e., Phe-257, Leu-260, Ala-261, Met-298, Leu299, Leu-331, Ile-336, Ile-339, Leu-428, and Trp-443) is in the LXR $\alpha$ C-terminal, which is the ligand binding domain. It also implied that DDT could compete for the ligand binding site of LXR $\alpha$ with LXR $\alpha$ agonist. Therefore, we speculated that DDT may impair ABCA1 expression by targeting LXR $\alpha$ directly. In summary, we identified for the first time that 
DDT could inhibit $\operatorname{LXR} \alpha$ expression and interfere with $\mathrm{A} \beta$ clearance. Furthermore, our results implied that DDT may have direct antagonizing effects on LXR $\alpha$ expression by binding to it (Figure 6). Our present study provides evidence for identifying the new targets of DDT-induced molecular pathway in $\mathrm{AD}$. It also provides a valuable experimental basis to explain how environmental factors, especially pesticides, affect AD. In the future, more definitive studies on mice and human are warranted to assess the effects of environmental factors on neurodegenerative disorders.

\section{DATA AVAILABILITY STATEMENT}

The raw data supporting the conclusions of this article will be made available by the authors, without undue reservation.

\section{REFERENCES}

Alzheimer's Association (2013). 2016 Alzheimer's disease facts and figures. Alzheimers Dement. 9, 208-245. doi: 10.1016/j.jalz.2016.03.001

Bates, K. A., Verdile, G., Li, Q. X., Ames, D., Hudson, P., Masters, C. L., et al. (2009). Clearance mechanisms of Alzheimer's amyloid-beta peptide: implications for therapeutic design and diagnostic tests. Mol. Psychiatry 14, 469-486. doi: 10.1038/mp.2008.96

Billioti De Gage, S., Moride, Y., Ducruet, T., Kurth, T., Verdoux, H., Tournier, M., et al. (2014). Benzodiazepine use and risk of Alzheimer's disease: case-control study. BMJ 349:g5205. doi: 10.1136/bmj.g5205

Caputo, V., Termine, A., Strafella, C., Giardina, E., and Cascella, R. (2020). Shared (epi)genomic background connecting neurodegenerative diseases and type 2 diabetes. World J. Diabetes 11, 155-164. doi: 10.4239/wjd.v11.i5.155

Corona, A. W., Kodoma, N., Casali, B. T., and Landreth, G. E. (2016). ABCA1 is necessary for bexarotene-mediated clearance of soluble amyloid beta from the hippocampus of APP/PS1 Mice. J. Neuroimmune Pharmacol. 11, 61-72. doi: 10.1007/s11481-015-9627-8

Davies, T. G., Field, L. M., Usherwood, P. N., and Williamson, M. S. (2007). DDT, pyrethrins, pyrethroids and insect sodium channels. IUBMB Life 59, 151-162. doi: 10.1080/15216540701352042

Di, S., Liu, R., Tian, Z., Cheng, C., Chen, L., Zhang, W., et al. (2017). Assessment of tissue-specific accumulation, elimination and toxic effects of dichlorodiphenyltrichloroethanes (DDTs) in carp through aquatic food web. Sci. Rep. 7:2288. doi: 10.1038/s41598-017-02612-4

Erkkinen, M. G., Kim, M. O., and Geschwind, M. D. (2018). Clinical neurology and epidemiology of the major neurodegenerative diseases. Cold Spring Harb Perspect. Biol. 10:a033118. doi: 10.1101/cshperspect.a033118

Finch, C. E., and Kulminski, A. M. (2019). The Alzheimer's disease exposome. Alzheimers Dement 15, 1123-1132. doi: 10.1016/j.jalz.2019. 06.3914

Fitz, N. F., Carter, A. Y., Tapias, V., Castranio, E. L., Kodali, R., Lefterov, I., et al. (2017). ABCA1 deficiency affects basal cognitive deficits and dendritic density in mice. J. Alzheimers Dis. 56, 1075-1085. doi: 10.3233/JAD-161056

Fleming, L., Mann, J. B., Bean, J., Briggle, T., and Sanchez-Ramos, J. R. (1994). Parkinson's disease and brain levels of organochlorine pesticides. Ann. Neurol. 36, 100-103. doi: 10.1002/ana.410360119

Frigo, D. E., Vigh, K. A., Struckhoff, A. P., Elliott, S., Beckman, B. S., Burow, M. E., et al. (2005). Xenobiotic-induced TNF- $\alpha$ expression and apoptosis through the p38 MAPK signaling pathway. Toxicol. Lett. 155, 227-238. doi: 10.1016/j.toxlet. 2004.09.008

Götz, A. W., Williamson, M. J., Xu, D., Poole, D., Le Grand, S., and Walker, R. C. (2012). Routine microsecond molecular dynamics simulations with AMBER on GPUs. 1. Generalized Born. J. Chem. Theory Comput. 8, 1542-1555. doi: $10.1021 /$ ct $200909 j$

\section{AUTHOR CONTRIBUTIONS}

All the authors listed have made a substantial, direct, and intellectual contribution to this work, and approved the submitted version for publication.

\section{FUNDING}

This work was supported by Natural Science Foundation Project of Chongqing, Chongqing Science and Technology Commission (cstc2019jcyj-msxmX0173). The authors express their gratitude for the support provided by National Natural Science Foundation of China (NSFC, \#82001434) and the Natural Science Foundation Project of Chongqing, Chongqing Science and Technology Commission (cstc2020jcyjmsxmX0149).

Greenwood, B. (2014). Treatment of malaria-a continuing challenge. N. Engl. J. Med. 371, 474-475. doi: 10.1056/NEJMe1407026

Hayden, K. M., Norton, M. C., Darcey, D., Ostbye, T., Zandi, P. P., Breitner, J. C., et al. (2010). Occupational exposure to pesticides increases the risk of incident AD: the Cache County study. Neurology 74, 1524-1530. doi: 10.1212/WNL. 0b013e3181dd 4423

Iraola-Guzman, S., Estivill, X., and Rabionet, R. (2011). DNA methylation in neurodegenerative disorders: a missing link between genome and environment. Clin. Genet. 80, 1-14. doi: 10.1111/j.1399-0004.2011.01673.x

Jack, C. R., Jr., Lowe, V. J., Weigand, S. D., Wiste, H. J., Senjem, M. L., Knopman, D. S., et al. (2009). Serial PIB and MRI in normal, mild cognitive impairment and Alzheimer's disease: implications for sequence of pathological events in Alzheimer's disease. Brain 132, 1355-1365. doi: 10.1093/brain/awp062

Jiang, Q., Lee, C. Y., Mandrekar, S., Wilkinson, B., Cramer, P., Zelcer, N., et al. (2008). ApoE promotes the proteolytic degradation of A $\beta$. Neuron 58, 681-693. doi: 10.1016/j.neuron.2008.04.010

Kazantseva, Y. A., Yarushkin, A. A., and Pustylnyak, V. O. (2013) Dichlorodiphenyltrichloroethane technical mixture regulates cell cycle and apoptosis genes through the activation of CAR and $\mathrm{ER} \alpha$ in mouse livers. Toxicol. Appl. Pharmacol. 271, 137-143. doi: 10.1016/j.taap.2013.05.008

Kelce, W. R., Stone, C. R., Laws, S. C., Gray, L. E., Kemppainen, J. A., and Wilson, E. M. (1995). Persistent DDT metabolite p,p'-DDE is a potent androgen receptor antagonist. Nature 375, 581-585. doi: 10.1038/375581a0

Kim, K. S., Lee, Y. M., Lee, H. W., Jacobs, D. R., Jr., and Lee, D. H. (2015). Associations between organochlorine pesticides and cognition in U.S. elders: national health and nutrition examination survey 1999-2002. Environ. Int. 75 87-92. doi: 10.1016/j.envint.2014.11.003

Kiyosawa, N., Kwekel, J. C., Burgoon, L. D., Williams, K. J., Tashiro, C., Chittim, B., et al. (2008). o,p'-DDT elicits PXR/CAR-, not ER-, mediated responses in the immature ovariectomized rat liver. Toxicol. Sci. 101, 350-363. doi: $10.1093 /$ toxsci/kfm 275

Koldamova, R., Fitz, N. F., and Lefterov, I. (2014). ATP-binding cassette transporter A1: from metabolism to neurodegeneration. Neurobiol. Dis. 72, 13-21. doi: 10.1016/j.nbd.2014.05.007

Laffitte, B. A., Joseph, S. B., Walczak, R., Pei, L., Wilpitz, D. C., Collins, J. L., et al. (2001). Autoregulation of the human liver receptor alpha promoter. Mol. Cell Biol. 21, 7558-7568. doi: 10.1128/MCB.21.22.7558-7568.2001

Li, G., Kim, C., Kim, J., Yoon, H., Zhou, H., and Kim, J. (2015). Common pesticide, dichlorodiphenyltrichloroethane (DDT), Increases amyloid-beta levels by impairing the function of ABCA1 and IDE: implication for Alzheimer's disease. J. Alzheimers Dis. 46, 109-122. doi: 10.3233/JAD-150024

Matsushima, A. (2018). A novel action of endocrine-disrupting chemicals on wildlife; DDT and its derivatives have remained in the environment. Int. J. Mol. Sci. 19:1377. doi: 10.3390/ijms19051377 
Medina-Diaz, I. M., Arteaga-Illan, G., de Leon, M. B., Cisneros, B., SierraSantoyo, A., Vega, L., et al. (2007). Pregnane X receptor-dependent induction of the CYP3A4 gene by o,p'-1,1,1,-trichloro-2,2-bis (p-chlorophenyl)ethane. Drug. Metab. Dispos. 35, 95-102. doi: 10.1124/dmd.106.011759

Morris, G. M., Huey, R., Lindstrom, W., Sanner, M. F., Belew, R. K., Goodsell, D. S., et al. (2009). AutoDock4 and AutoDockTools4: automated docking with selective receptor flexibility. J. Comput. Chem. 30, 2785-2791. doi: 10.1002/jcc. 21256

Mozzicafreddo, M., Cuccioloni, M., Bonfili, L., Cecarini, V., Palermo, F. A., Cocci, P., et al. (2015). Environmental pollutants directly affect the liver $\mathrm{X}$ receptor alpha activity: Kinetic and thermodynamic characterization of binding. J. Steroid Biochem. Mol. Biol. 152, 1-7. doi: 10.1016/j.jsbmb.2015. 04.011

Niculescu, A. B., Le-Niculescu, H., Roseberry, K., Wang, S., Hart, J., Kaur, A., et al. (2020). Blood biomarkers for memory: toward early detection of risk for Alzheimer disease, pharmacogenomics and repurposed drugs. Mol. Psychiatry 25, 1651-1672. doi: 10.1038/s41380-019-0602-2

Pierce, L. C., Salomon-Ferrer, R., Augusto F. de Oliveira, C., McCammon, J. A., and Walker, R. C. (2012). Routine access to ms time scale events with accelerated molecular dynamics. J. Chem. Theory Comput. 8, 2997-3002. doi: $10.1021 / \mathrm{ct} 300284 \mathrm{c}$

Realdon, O., Rossetto, F., Nalin, M., Baroni, I., Cabinio, M., Fioravanti, R., et al. (2016). Technology-enhanced multi-domain at home continuum of care program with respect to usual care for people with cognitive impairment: the Ability-TelerehABILITation study protocol for a randomized controlled trial. BMC Psychiatry 16:425. doi: 10.1186/s12888-016-1132-y

Richardson, J. R., Roy, A., Shalat, S. L., von Stein, R. T., Hossain, M. M., Buckley, B., et al. (2014). Elevated serum pesticide levels and risk for Alzheimer disease. JAMA Neurol. 71, 284-290. doi: 10.1001/jamaneurol.2013.6030

Salomon-Ferrer, R., Götz, A. W., Poole, D., Le Grand, S., and Walker, R. C. (2013). Routine microsecond molecular dynamics simulations with Amber on GPUs. 2. Explicit solvent particle mesh Ewald. J. Chem. Theory Comput. 9, 3878-3888. doi: 10.1021/ct400314y

Sanner, M. F. (1999). Python: a programming language for software integration and development. J. Mol. Graph. Model. 17, 57-61.

Singh, N., Chhillar, N., Banerjee, B., Bala, K., Basu, M., and Mustafa, M. (2013). Organochlorine pesticide levels and risk of Alzheimer's disease in north Indian population. Hum. Exp. Toxicol. 32, 24-30. doi: 10.1177/0960327112456315

Skerrett, R., Malm, T., and Landreth, G. (2014). Nuclear receptors in neurodegenerative diseases. Neurobiol. Dis. 72, 104-116. doi: 10.1016/j.nbd. 2014.05.019

Sousa Da Silva, A. W., and Vranken, W. F. (2012). ACPYPE - anteChamber PYthon parser interfacE. BMC Res. Notes 5:367. doi: 10.1186/1756-0500-5-367

Terwel, D., Steffensen, K. R., Verghese, P. B., Kummer, M. P., Gustafsson, J. A., Holtzman, D. M., et al. (2011). Critical role of astroglial apolipoprotein E and liver $\mathrm{X}$ receptor-alpha expression for microglial $\mathrm{A} \beta$ phagocytosis. J. Neurosci. 31, 7049-7059. doi: 10.1523/JNEUROSCI.6546-10.2011

Trott, O., and Olson, A. J. (2010). AutoDock Vina: improving the speed and accuracy of docking with a new scoring function, efficient optimization and multithreading. J. Comput. Chem. 31, 455-461. doi: 10.1002/jcc.21334 van Wendel De Joode, B., Wesseling, C., Kromhout, H., Monge, P., Garcia, M., and Mergler, D. (2001). Chronic nervous-system effects of long-term occupational exposure to DDT. Lancet 357, 1014-1016. doi: 10.1016/S0140-6736(00) 04249-5

Wahrle, S. E., Jiang, H., Parsadanian, M., Hartman, R. E., Bales, K. R., Paul, S. M., et al. (2005). Deletion of Abcal increases $A \beta$ deposition in the PDAPP transgenic mouse model of Alzheimer disease. J. Biol. Chem. 280, 43236-43242. doi: 10.1074/jbc.M508780200

Wahrle, S. E., Jiang, H., Parsadanian, M., Kim, J., Li, A., Knoten, A., et al. (2008). Overexpression of ABCA1 reduces amyloid deposition in the PDAPP mouse model of Alzheimer disease. J. Clin. Invest. 118, 671-682. doi: 10.1172/ JCI33622

Wang, J., Wang, W., Kollman, P. A., and Case, D. A. (2006). Automatic atom type and bond type perception in molecular mechanical calculations. J. Mol. Graph. Model. 25, 247-260. doi: 10.1016/j.jmgm.2005.12.005

Wang, J., Wolf, R. M., Caldwell, J. W., Kollman, P. A., and Case, D. A. (2004). Development and testing of a general amber force field. J. Comput. Chem. 25, 1157-1174. doi: 10.1002/jcc.20035

Wang, L., Zhang, X., Lu, Y., Tian, M., and Li, Y. (2014). Dynamic changes of Apo A1 mediated by LXR/RXR/ABCA1 pathway in brains of the aging rats with cerebral hypoperfusion. Brain Res. Bull 100, 84-92. doi: 10.1016/j.brainresbull. 2013.11.004

Wildsmith, K. R., Holley, M., Savage, J. C., Skerrett, R., and Landreth, G. E. (2013). Evidence for impaired amyloid beta clearance in Alzheimer's disease. Alzheimers Res. Ther. 5:33. doi: 10.1186/alzrt187

Wnuk, A., Rzemieniec, J., Przepiórska, K., Wesoowska, J., Wójtowicz, A. K., and Kajta, M. (2020). Autophagy-related neurotoxicity is mediated via AHR and CAR in mouse neurons exposed to DDE. Sci. Total Environ. 742:140599. doi: 10.1016/j.scitotenv.2020.140599

Zelcer, N., Khanlou, N., Clare, R., Jiang, Q., Reed-Geaghan, E. G., Landreth, G. E., et al. (2007). Attenuation of neuroinflammation and Alzheimer's disease pathology by liver X receptors. Proc. Natl. Acad. Sci. U S A 104, 10601-10606. doi: 10.1073/pnas.0701096104

Zhao, J., Fu, Y., Liu, C. C., Shinohara, M., Nielsen, H. M., Dong, Q., et al. (2014). Retinoic acid isomers facilitate apolipoprotein E production and lipidation in astrocytes through the retinoid $\mathrm{X}$ receptor/retinoic acid receptor pathway. J. Biol. Chem. 289, 11282-11292. doi: 10.1074/jbc.M113. 526095

Conflict of Interest: The authors declare that the research was conducted in the absence of any commercial or financial relationships that could be construed as a potential conflict of interest.

Copyright (c) $2021 \mathrm{Wu}, \mathrm{Hu}$, Song and Li. This is an open-access article distributed under the terms of the Creative Commons Attribution License (CC BY). The use, distribution or reproduction in other forums is permitted, provided the original author(s) and the copyright owner(s) are credited and that the original publication in this journal is cited, in accordance with accepted academic practice. No use, distribution or reproduction is permitted which does not comply with these terms. 